\title{
OPPORTUNITIES AND POLICY CHALLENGES OF DIGITAL ECONOMY TO SMALL REGIONS: THE CASE OF GIPUZKOA
}

\author{
OPORTUNIDADES Y RETOS POLÍTICOS DE LA ECONOMÍA DIGITAL PARA LAS REGIONES PEQUEÑAS: EL CASO DE GIPUZKOA
}

\author{
Andoni Eizagirre \\ Mondragon University, Spain \\ aeizagirre@mondragon.edu
}

\begin{abstract}
Nations and territories have new and varied challenges with respect to promoting continuous growth in the economy. The purpose of this article is to determine the opportunities and difficulties faced by the territory of Gipuzkoa in the field of economics. In interviews and focus groups with the principle agents of the territory, the unified commitment to industry over the last decades is unanimously appreciated. This commitment involves the complete transformation of the social and economic structure of the territory. However, disparities in business dynamism are evident, and the capacities and resources of companies to bring industry up to date in the digital economy and respond to new competitive factors are very different. This being the case, different perspectives are emerging to respond to challenges among agents. Nevertheless, two general issues are agreed upon: the territory is conceptualized as an active agent, and the need for updating the innovation system is recognized. This makes it possible to share strategies and to respond in a cooperative way to productive specialization.
\end{abstract}

Key words: digital economy, industry, territorial strategy, Gipuzkoa, discourse analysis.

Resumen: Las naciones y los territorios tienen nuevos y variados desafíos con respecto a la promoción del crecimiento continuo en la economía. El propósito de este artículo es determinar las oportunidades y dificultades que enfrenta el territorio de Gipuzkoa en el campo de la economía. En entrevistas y grupos de discsuón con los principales agentes del territorio, se aprecia unánimemente el compromiso unificado con la industria en las últimas décadas. Este compromiso implica la transformación completa de la estructura social y económica del territorio. Sin embargo, las disparidades en el dinamismo empresarial son evidentes, y las capacidades y recursos de las empresas para actualizar la industria en la economía digital y responder a los nuevos factores competitivos son muy diferentes. Siendo este el caso, están surgiendo diferentes perspectivas para responder a los desafíos entre los agentes. Sin embargo, se acuerdan dos cuestiones generales: el territorio se conceptualiza como un agente activo y se reconoce la necesidad de actualizar el sistema de innovación. Esto permite compartir estrategias y responder de manera cooperativa a la especialización productiva.

Palabras clave: economía digital, industria, estrategia territorial, Gipuzkoa, análisis del discurso.

\section{Introduction}

\section{The knowledge society and new challenges}

In the global economy, the economic and social development of any one country depends on many factors. Some of them, though it may be partially, depend on local decisions (Rodrik, 2018). On the one hand, in the continuous growth of the economy, inflation, public and private debt, financial behavior, research, development, and innovation are of great importance. On the other hand, together with macroeconomic balance, there are also factors that affect growth effectively, for example, industrial policy, human capital, private economic activity, and the vocation and structural capacity for constant transformation of the economy, among others (Mazzucato, 2018). 
At the same time, the nation's strategies must be adjusted and adapted according to the productive structure of the technological era and the local economy (Pérez, 2002). In this sense, in the knowledge society, the effort to revive and revitalize the productive system emerges as a challenge to respond to technological transformation and the business model, to the extent that the conception of industry is completely changing. In recent decades, together with providing technological convergence on the global level (Baldwin, 2016), productivity is closely linked to productive specialization, as well as to the factors used in production and their quality (Stiglitz \& Greenwald, 2014). Specifically, investment intensity, qualification of the labor factor, the use of information technology, the provision of intangible assets, and the quality of business management, among other things, hold special importance in the growth of the productivity of the economy of a country. By financing, together with companies, other public and private institutions in the country, they determine productivity with their decisions regarding education, public policy, and regulation. Of course, the economy of the nation is also very dependent on other factors, such as interest rates, fuel prices investment, and the evolution of geopolitical issues in global commerce (Rodrik, 2011). One way or another, all of these factors, with their variable relative weights, affect productivity, and thus, by extension, company strength, and competitive advantage in general, international options, and also the GDP of the population., currency policy, demography, the composition of the employed population, public

In other words, in the global economy, countries' welfare, cohesion, and standard of living are dependent to some extent on the territory in question and its economic efficiency. Indeed, productive and financial restructuring on the international level concentrates stages of specialization in the innovation chain in specific spaces. However, territories and local agents must be able to respond to new and more competitive factors in the knowledge society. Given this situation, strategic alignment among territorial agents, governance, technological capabilities, and innovation intensity are of particular importance (Mazzucato, 2016).

Knowledge society, however, also has more new and unique challenges. One of these, the most obvious, and often the one that does not merit as much attention as necessary, is that the importance of manufacturing has been falling in the productive structure of Europe. (In European countries this loss was heterogeneous in the fall of the relative value of production, but it was obvious and homogeneous in the case of employment. This transformation is closely linked to developments in demand, technology, and international commercial and financial integration.) As a result, technological transformation has placed us in a very different context: the industrialization process facilitated social mobility, but with the fall in the importance of employment in manufacturing, differences in income distribution have been noted. This fall is not enough, however, to adequately explain the erosion of social cohesion. On the contrary, a comparative point of view shows that countries whose manufacturing has lost ground in productive structure are those with the weakest technological intensity in manufacturing, and ones that are also suffering adverse effects in technological change and the automation of industrial functions (Ridao-Cano \& Bodewig, 2018). It is precisely in a nation's social and economic development that the combination of these factors has an effect. Likewise, the transformation of industrial society has had two distinct attributes: one is that employment in the industrial sector has been adjusted in a short time over barely three decades; and the other is that the automation process has led to significant divergence between productivity and labor income (Acemoglu \& Restrepo, 2018).

The arrival of intelligent machines in the European labor market and in the distribution of income is having disruptive effects. The European countries, however, have not only changes in work and local divergence in income levels, but also other challenges, as other world contexts gain in importance; the contexts include the following, among others: demographic dispute, scientifictechnological knowledge, digital transformation, convergence of levels of income on the global level, the displacement of the world toward the Pacific, weakening of the subjective state of security, the new composition of employment, dispute of the Welfare State, the ecological crisis, immigration, and the future of Europe (Castells, 2018). 


\section{Territorial agents discuss new challenges}

The general purpose of the present research is to determine what sorts of challenges and opportunities the province of Gipuzkoa and local agents have in technology, in governance, in the business model, in financing, and in competitive factors overall. There are many different ways to meet such a goal; for example, we could analyze the organization of innovation systems, competitiveness programs, tools, and resources, and the interests and competencies of the agents (see for example Morgan, 2016; Uyarra et al., 2017). In the present research, however, focus has been placed on discussion about challenges in Gipuzkoa by the primary agents of the territory. Specifically, the topic for study is the interpretation of socio-economic phenomena by agents from the territory of Gipuzkoa.

There are several reasons in favor of becoming familiar with the agents' perceptions. On the one hand, culture and subjective principles are important in economic activity, perspectives and discussion have a strategic importance as far as the economy is concerned, as well as a cultural dimension. Additionally, the narrative of the future, one way or another, has an effect on reality, whether when designing strategies, properly implementing plans, or organizing resources, for example. In the end, in order to understand agents' strategies (intensity and orientation), even if only partially, it is helpful to analyze their discourse.

Agents' interpretations are of special importance, furthermore, in these times in which the structures, principles, and values of society are in at state of constant change. Indeed, when stable, continuous, and predictable routes break down, the strategic capacity of human agents to focus on uncertainty and complexity takes on unusual importance. In other words, agents' views, perceptions, and attitudes - together with other structural and institutional variables - frame decisions in interpreting the territory's challenges, selecting one solution or another, and effectively developing it. In the final analysis, strategic territorial competencies guide confidence, motivation, and expectations among agents, as do shared representations. Likewise, agents' discourse reveals in what cognitive, sentimental, and emotional landscape important decisions are made.

More specifically, the strategic capacity of the territory is closely linked to two variables. One is reflexivity (how agents take into consideration themselves and other agents in the social context and how agents reflect on the social context in the light of their situation and their choices). The other is relationality (the set of the agents' social relationships and relationships among relationships, and their quality and intensity). Reflexivity and relationality tend to orient the strategic capacity of the agents of the territory improvement and growth - in contexts of uncertainty and complexity. This being the case, the capacity of territorial agents to respond to technological and economic challenges, among other things, is conditioned by the way in which it relates to context. The present research examines these issues.

\section{Methodology}

In order to become familiar with the discourses of the territory's agents, two primary research techniques were used: interviews and focus groups, both semi-structured and open (Table 1). All were conducted in the spring of 2017. Since the second half of 2015, the economy has shown a steady growth rate. Because of that, in discourses about the territory, concerns about strategies have again held primary importance.

The selection of the socio-economic agents of the territory was carried out according to three criteria. First, the helices of the innovation system (government and administration, knowledge organizations, financial entities, companies) were taken into account. Next, the historical perspective and the inter-generational viewpoint were considered. This makes it possible to determine what kind of continuity, breaks, and innovation there were in the remodeling and revival of the productive system of the territory, and in general, in the transformation of the economy in a vocation and structural capacity. Finally, the agents of the system were considered as agents of the innovation system, as were system experts and researchers. All together, a total of 34 people participated: interviews were done with 9 , and the rest took part in focus groups. ${ }^{1}$

\footnotetext{
${ }^{1}$ The present research also focused on the welfare and socialization policies of the territory. For this purpose, interviews and monographic focus groups were conducted. Since the present article focuses on economic disputes in the territory, it does not provide details on welfare or policies.
} 
Table 1. Outline for interviews and focus groups

\begin{tabular}{|c|c|c|}
\hline Factor & Category & Indicators \\
\hline \multirow[t]{2}{*}{$\begin{array}{l}\text { What is the } \\
\text { participant's general } \\
\text { point of view? } \\
\text { (Economic culture) }\end{array}$} & $\begin{array}{l}\text { How does the participant describe social } \\
\text { reality? }\end{array}$ & $\begin{array}{c}\text { Social structure } \\
\text { Moral culture and productive } \\
\text { innovation } \\
\text { Social capital } \\
\text { Social change } \\
\text { Globalization and territorial } \\
\text { power }\end{array}$ \\
\hline & $\begin{array}{l}\text { What is his or her reading of development, } \\
\text { competitiveness, and their key issues? }\end{array}$ & $\begin{array}{c}\text { Social agents } \\
\text { Culture } \\
\text { The productive fabric } \\
\text { The innovation system } \\
\text { Institutions }\end{array}$ \\
\hline \multirow{3}{*}{$\begin{array}{c}\text { What is the } \\
\text { participant's } \\
\text { assessment of } \\
\text { territorial dynamics? } \\
\text { (Economic } \\
\text { conceptualization of } \\
\text { the territory) }\end{array}$} & $\begin{array}{l}\text { How is the territory understood in terms of } \\
\text { development and economic competitiveness? }\end{array}$ & $\begin{array}{l}\text { Macroeconomics } \\
\text { Human capital } \\
\text { Industry } \\
\text { Governance } \\
\text { Values }\end{array}$ \\
\hline & $\begin{array}{c}\text { What are the objectives of a country? How are } \\
\text { they conceptualized? }\end{array}$ & $\begin{array}{c}\text { Competitiveness } \\
\text { Welfare } \\
\text { Opening } \\
\text { Efficiency }\end{array}$ \\
\hline & $\begin{array}{c}\text { What is the position, importance, and function } \\
\text { of agents in territorial dynamics? How should } \\
\text { agents interact? }\end{array}$ & $\begin{array}{l}\text { Strategy } \\
\text { Cooperation } \\
\text { Learning }\end{array}$ \\
\hline $\begin{array}{l}\text { What is the } \\
\text { participant's reading } \\
\text { of the territory? } \\
\text { (Diagnosis of the } \\
\text { territory of } \\
\text { Gipuzkoa) }\end{array}$ & $\begin{array}{c}\text { How do we evaluate the vocation and } \\
\text { structural capability for continuous } \\
\text { transformation of the economy of the territory } \\
\text { of Gipuzkoa? }\end{array}$ & $\begin{array}{c}\text { Path } \\
\text { Challenges } \\
\text { Transformational capacity } \\
\text { Treaties } \\
\text { Market research }\end{array}$ \\
\hline
\end{tabular}

Source: own elaboration.

In the following pages, we report the main outcomes of the interviews and focus groups: first and foremost, an assessment of the recent past and an evaluation of the unified commitment to the industry will be presented. The opportunities and difficulties of the industrial economic structure will then be specified: duality between companies is evident and this strengthens the capabilities and resources of companies to respond to new competitive factors because they are very different. Next, we will debate two complicated issues that affect territorial businesses in the global economy: foreign capital, and opportunities for public policies in the interests of companies. We will then compare points of view regarding the leadership that companies and other agents need in order to 
update governance and the innovation system. And finally, general recommendations will be given for updating the governance system.

\section{A peculiarity of the territory: a unified commitment to industry}

The diligent behavior of agents in recent decades to revive the productive sector of the territory is noteworthy. Indeed, the unusual commitment to renewed industry in the economic structure made together by both organizations and people has been a distinguishing feature of the territory. To some extent, these shared efforts have been employed to learn lessons and clarify how to respond to the development and efficiency of the territory.

In the 1980s, the territory remodeled and revitalized the productive system. This was a very distinctive period of time. On the one hand, significant challenges arose at this time, such as the crisis of traditional industry, the restructuring of the international economy and production, European economic integration, globalization, and a slowdown in growth. On the other hand, the power of public administrations increased, and territorial agents prioritized industry, and its additional and complementary activities, with a broad consensus. Because of this, investments were made to revive economic activity in research and technological development, in industrial land use, in public-private cooperation in the fields of knowledge and technology, in financial aid to companies thanks to the liquidity of savings banks, in the development, infrastructure, and internationalization of new technological and industrial projects, etc. As a result of all this, industry made an important contribution to added value. In this context, it was possible to progressively replace intensive industrialization and the manual laborer with low levels of training and education with another model.

There has been wide agreement regarding economic strategy in the field of industry and this has facilitated a regional dimension. That is, the restructuring of industrial economic structure compared to business strategy - must be comprehensive and unifying, and the conditions for accomplishing this are present in the territory. In the perceptions of some agents there has been narrow and partial behavior (the regional government claiming center stage, designing a target and top-down strategy, directing policies primarily to certain sectors and companies). But generally, territorial agents have been involved in aligning knowledge (training, education, research, knowledge transfer, innovation), economic promotion, financing, and the value system with industrial economic strategy. In this sense, and with the attendant ups and downs and difficulties, the ability to network is considered to be valuable, as are cooperation, trust, and the division of responsibilities among territorial agents.

The rate of industrial employment and its importance among the employed population confirm the unusual commitment made together by territorial agents in favor of renewed industry in the economic structure. Closely linked to this, in just a few decades, the productive system related to industry and technology strengthened the social and economic structure based on efficiency, innovation, training and intelligence. Because of this, the ability to reorganize industry and extend the productive model, a beneficial macroeconomic environment, a medium-high level of education of the population, institutionalized modernization, the significance of technological projects, the ability to network among agents, productivity, small and medium-sized companies that are firmly established in the territory, progressive internationalization, and an ample income for the population, among other things, are valued as strengths of the territory. Another feature of the territory is that labor markets and productive models have been very important in social cohesion. That is, the main feature of welfare has been the economic transfer of wages (salaries, contributory benefits). In other words, the strongest social policy in the territory has been economic policy. In this sense, social inclusion and access to social rights have been based to a large extent on salaried income.

However, in recent years a number of disparities have become apparent in the territory. Some of these have been linked to different efforts to remodel the productive system, for example, different contributions to added value by different sectors, and divisions between companies (there are obvious differences in the innovation efforts, investment in $\mathrm{R} \& \mathrm{D}$, technological level, and ability to internationalize of different companies). The financial crisis of 2008 confirmed these concerns with the loss of many companies and with the obvious duality that emerged in the transition among companies to digital industry (new business models, technological 
transformation, diversification, an innovative base, connections with agents). Furthermore, asymmetries in business dynamism have corroborated differences in the territory from valley to valley; advanced dynamics (efficient and competitive industry, an educated population, training sites) are concentrated in specific places.

There are also other disparities, however. The fact that territorial cohesion and welfare are dependent in a way on the labor market has revealed a social divide. On the one hand, there is a clear split between the level of training of the employed population and the training process and job market demand (the relatively small significance of higher vocational training and problems in responding to job offers; the low level of education among older workers; the increase over a few decades in the population that has completed university studies, and the lack of adjustment to the productive fabric of the territory). On the other hand, it is becoming more and more difficult for employment to serve as a means of social integration; the territorial labor market has problems in generating employment for the active population and in getting people to work (chronic unemployment, difficulties in stabilizing work profiles). This has been a great challenge for the territory. At the same time, however, social protection and tax systems have had significant difficulties in reducing the poverty rate. At the same time, income to guarantee revenues provides suitable options for mitigating poverty (extension and intensity), but it has limited capacity to reach those who need it, and the territory does not have jurisdiction to determine certain aspects of income (regulation of work relationships, the pension system, unemployment benefits). With all of these issues, there is a need to differentiate employment policy from social policy. The territory must necessarily face this challenge in an innovative way.

\section{Opportunities and difficulties of industrial economic structure}

In the last two decades, the industrial economic structure of the territory has had to make various adjustments. In the opinion of agents, these adjustments have served to improve the business situation but there are still many challenges ahead of us. Indeed, competitiveness factors have reemerged and increased, and the way we understand industrial policy has changed completely.

\subsection{Disparities among companies}

With respect to territorial industry and business structure, a duality between companies emerges in the diagnosis of the agents. In the territory, there are companies that have the ability to compete in an international economy, but gaps between companies are also evident. The adjustments of recent years (opening and closing of businesses) have, to some extent, provided a solution for this, but parts of the problem still remain. According to the present research, some companies have their own products or processes, they are committed to innovation strategy, and they have the ability to compete in international markets. In this case, the businesses in question have their own path, as well as their particular vision and strategy. But side by side with this we find a very different situation, that of small businesses (small businesses operating in traditional sectors), whose situation is weak and very dependent, and who have very limited opportunities and resources looking toward the future.

In many cases, territorial industry has many weaknesses. Some of these are associated with companies' outdated organization and supply. Other problems are associated with companies' capabilities and efficiency: the shortage of human resources and the limiting of functions to administrative issues; the lack of professionalization in the management of people, strategies, and customers; the lack of investment opportunities and culture; the lack of funding margins and difficulties in attracting investment; limited information. On the other hand, the majority of companies remain on the sidelines in government competitiveness plans, and administrations have difficulties in reaching many companies. At the same time, factory dependence on multinational companies limits potential opportunities in many ways. The limitations and problems involved in promoting business efficiency are numerous. On the other hand, with automation, the limits of the mass production industry will become evident.

The nature and objectives of industry have been altered, and market cycles are becoming shorter and shorter at the same time that protection is demanded for flexibility, specialization, and diversification. In this context, agents indicate that 
it is necessary to pay attention to advanced business management, technological capability, innovation intensity, financing capacity, and new business models. However, new competitiveness factors are increasing gaps between companies. Indeed, just as companies that are medium-sized and technologically competitive have opportunities to move forward and revitalize - with innovation efforts, R\&D investment, alliances, people's abilities and competences, and new business models - small and medium-sized companies generally have difficulty influencing competitive factors. Furthermore, gaps between businesses have an impact on company alignments, for example, since anchor businesses have additional dependence issues, and the difficulty of businesses to adapt to the digital transformation is also a problem for the competitive strategy of the territorial economy.

Three areas of work are proposed. First, when collaboration is encouraged between organizations and agents to influence technological, organizational and social innovation in companies, facilitatory initiatives are required to immerse medium-sized companies, and especially small ones, in these strategies. Second, it is considered essential to strengthen alliances and networking between anchor companies and complementary companies, and thus to strengthen companies' technological and productive capacity and provide collaborating businesses with international agreements. Finally, it is essential to create new companies in the territory, ones that will be able to offer new products, technologies, and services, and that will respond to the new employment composition.

\subsection{Competitiveness and industrial policy}

There is already a long history of responding to these initiatives and new competitive factors. That is, despite the 2008 financial crisis, the productive structure of the territory was maintained and strategic activities (competitive areas, facilitatory technology, priority markets) had already been planned. In other words, in order to update economic efficiency and the volume, composition, and quality of employment, industrial transformation, the promotion of new sectors, intangible elements, and an expansion business model (how to use technology) had already been defined as determining factors. In this sense, the territory had already paved the way toward responding to challenges.

The greatest change for the territory thus lies in the ways in which we understand industrial policy, that is, it lies in technological transformation as a new challenge for competitiveness and especially in new business models. According to this, regions should specialize not only in sectors or clusters, but also in value chains in specific districts. But industrial transformation goes beyond simply making machines or the challenge of innovating the technological product with the machine. Furthermore, added value is also found progressively in the business model (customer solutions, services, quality, price) and has implications for investment as well as for business organization and culture. Industrial transformation and the restructuring of international production are among the main challenges, in fact, that have to do with the new business model (comprehensive and advanced provision of services). Companies that participate in the international market will find differentiation in the available services - the ability to design a customer solution in the market; product design and management of its implementation; providing solutions to problems and transferring knowledge. In order for companies to compete internationally, investment is indispensable, as is the management of maintenance service and employees, and in this sense, financing, management, and training will be essential requirements. In the same way, The demands of the client include not only the capacity of the workforce and the company, but also organizational and cultural transformation (comprehensive care, instant response to international orders, availability).

In addition, in competitive strategies, on the other hand, industrial policy must overcome the strict - classical - conceptualization of industry and focus also on new activity. In this sense, creating wealth also means figuring out where and how to create it. It is clear that the territory has strengths and ample experience to move forward with advanced craftsmanship. However, it will be necessary to identify and establish new areas of wealth and to focus on intelligent specialization. This being the case, the specializations of the industry will need to be taken into account, including among other things, lifestyles, social needs and health in general (palliative care, 
dependence, social welfare), as well as energy, the environment, housing, and mobility.

Updating competitiveness and industrial policy, however, also affects how agents interact. On the one hand, since the efficiency of companies is associated to some extent with the capacities of the territory (training, education, research, knowledge transfer, innovation, financing, organization), the relationships among public, private, and community agents take on special importance. Specifically, two challenges arise: one is to clarify the identity, responsibility, and role of agents; the other is to strengthen relationships - relationship intensity, quality, and density - among agents. On the other hand, however, public administrations also have fragmented and partial plans (higher education, science and technology, internationalization, industry) for the area which must inevitably be complemented by more and more general plans. This is no small feat since it is based on the sharing of competences among territorial organizational institutions. The definitions of strategy and tools must also be rethought in the light of the possibilities of a global perspective and decentralized spaces. All of these challenges related to relationships are also a determining factor of competitiveness.

\section{Company becoming established in the territory}

Companies in the territory that are affected by technological changes and new business models must update their strategies. The debate about financing is one of the most complicated discussions. In this sense, the size and structure of companies in the territory will, to some extent, be determining factors in the effort to place added value and innovation at the center of strategies. The controversy among agents about company financing has caused debate. However, often differences are emphasized without examining what the opposing views may be. Furthermore, all parties agree on the importance of the territory in economic activity and entrepreneurial dynamism.

\subsection{Company growth and foreign capital}

Territorial weaknesses mean being weak in the financial industry and having lost savings banks as financial tools. In order to understand how the decision-making capacity in the area of economics has eroded in the territory and what kind of challenges arise because of financing, however, several other dynamics of the global contexts must also be taken into account. For example, companies are large in the global market and productions chains are fragmented within the global geography; the restructuring of production globally promotes business concentration processes. That is, alliances, mergers, purchases, and corporate operations are used as competitive factors. The interests, options, and strategies of local agents determine conditions, and economic policies in particular are determined at more general levels of government; these include currency policy and foreign trade (tariffs and fees, intellectual property rights, the flow of capital across borders, dispute resolution procedures, harmonization of standard regulations), among other things. The financialization and deregulation of the economy exacerbates policy margins. In the new economic context (globalization, international trade, technological change, labor market restructuring), many variables thus affect the financing and competitiveness of companies.

In this sense, the debate is open on foreign capital. According to agents who are in favor of attracting foreign capital, there are effective companies in the territory that have the opportunity to expand the business or grow in the market, and this is feasible through alliances or by opening up to new financial markets (investment funds, multinational companies, risk funds). Since companies' added value is associated with technological products and especially the new business model, attracting investment is considered to be one of the most important tasks of companies and of the territory in general. Moreover, the industrial economic structure of the territory is significant. Furthermore, opportunities for attracting foreign funds are real since not only companies but also the general context of the territory can attract them: the territory is composed of small and medium-sized businesses, companies are competitive and have savings or small debts, and the territory has developed an industrial ecosystem. Thus, companies in the territory are attractive for international investment. Managing this will define business morphology and business configuration in the territory in the coming years. However, in the opinion of those who consider attracting foreign capital as a wager, there are problems. The culture of territorial employers 
(believing in projects, business leadership, valuing autonomy) and the traditional roots of the territory bring about a certain resistance, for one thing because foreign capital has a number of requirements (demands to change corporate governance, problems with autonomy and control). Because of this, in order to respond to the primary challenges faced by companies today (attracting and retaining talent, advanced management, comprehensive and quality customer-based service, internationalization, and diversification), some agents clearly point out the need to provide cultural and mental change in order to understand and do business.

Specifically, companies would need to generalize a certain number of changes in order to compete and revitalize: open companies to new markets, accept foreign capital, redefine a territorial sense of belonging, and expand emotional ties and make them more permeable, among other things. Those who expose this need, however, accept that alliances, mergers and financing (multinational, investment funds, risk funds) open huge challenges, specifically, how to guarantee foreign capital for the industrial productive structure and how to do this continuously. Agents who value foreign capital have a specific hope: to strengthen the territory and its companies; however, this hope can be dashed if control of business strategy is lost.

\subsection{Companies and becoming established in the territory}

Public policies in the new arena can also formulate norms to regulate plans to retain companies in the territory. In the political field, there are a number of partial plans and initiatives in effect that are associated with promoting public participation and finances. Complementary measures include employee participation initiatives so that employees can hold power in company management, strategic decisions, and the distribution of benefits and company capital. At the same time, a component of the same strategy would be cooperation among companies in the territory, that is, strengthening cooperation and collaboration among companies to open global markets. The need to strengthen cooperation networks among companies and between companies and other organizations is evident.

By extension, the agents suggest continuing to create an effective context for territorial companies and making the most of the factors and resources that influence competitiveness (curricular alignment between higher education organizations and businesses, strengthening lifelong learning and collaborative research; consider the importance of market contracts in the activity of technological centers and reflect on performance in productive results, and promoting and facilitating the mobility of workers in the innovation system from one organization to another, among other things).

In addition to these initiatives, subjective principles, aspirations, and motivation are also regarded as important dimensions of the company. A new business culture can be based on more robust and resilient organizations. The importance of human capital has been noted (in productivity, the creation of added value, knowledge absorption, and competitiveness); the business model opens up the challenges of organization and entrepreneurship. The complexity of business organization and innovation is one of the motivations for transforming company participation. In efforts to update the productive industrial fabric, it is considered important not only technological change and international trade, but also human capital and the new business model, are considered important.

Company participation, in this sense, requires people to feel immersed in the business context, which to some extent is associated with wages, recognition, and initiatives for progress and decision-making. There are several links in the chain of participation on the cognitive and normative plane, some of which are associated with knowledge, communication, and the management of work relationships, and require educational resources and investment (training, preparation, and continuing education); some are related to workers' expectations, ambitions, and recognition (wages, pioneering the development of initiatives); and some are related to subjective and moral principles (participants' aspirations, vocation, and motivation). To some extent, participation can extend not only to work relationships and management, but also to profit distribution and ownership of the company. In order to retain skilled labor and talent - as a factor of competitiveness - companies in the territory will need to assign more and more importance to these issues.

Due to the nature, size, and capabilities of companies in the territory, there are difficulties in 
competing with the initiatives of international companies (wages, prestige, status). Along with this, it is expected that the professional biographies and career paths in the industry will change completely (short-term work, greater mobility), that pleasant contexts will be demanded (taking people's lifestyles into account), and that personal and professional development will be valued (industrial ecosystem). This will completely change the company's context and dynamics. Specifically, the territory must behave as an active agent for various initiatives, including a format for skilled labor, attracting and retaining workers, effective territorial development (competitive context, advanced infrastructure and resources, collaborative system of governance), and subjective principles and moral culture (cooperation, initiative, desire to work, sociability, accountability), the latter of which also has close ties with productive innovation.

In the agents' opinion, there are real opportunities in entrepreneurship and in general economic policy to reach strategic agreements in the territory in various areas, for example, to protect and transform the industry, to create quality employment, to promote technological and organizational innovation, and to inspire company workers to participate. There are opportunities, if space is shared, to gradually bring different perspectives closer to each other, to debate concepts, and to create confidence. Among the agents of the territory, this idea and this purpose are robust and general.

\section{Company strategy and territorial strategy}

In the economic development of the territory, the importance of companies in industry and technology is unanimously accepted and supported. There is consensus among agents regarding various premises: the importance of specialization, establishing a fundamental difference and close collaboration that will be complementary to territorial agents, and valuing human capital and skilled labor when restructuring production processes in the global economy. However, there are different readings on the ways to design and develop promotional and competitive policies. With all this, since agents unanimously recognize the territory as an active agent, principles and actions are powerful options for sharing.

\subsection{The company in the global market}

Among some of the territory's agents we find the following point of view: through quality and price, it is the market that establishes and determines opportunities, while the company, on the other hand, can provide a comprehensive and flexible service by being familiar with its customers' needs and by specializing and creating value in design and manufacturing. According to this, since companies have market knowledge in the global economy, they should have agents at the center of economic and competitiveness strategies. That is to say, when updating the responsibilities, roles, and accountability of territorial agents, the focus should be on the powers, needs, and goals, of the companies in question.

However, they mention a number of difficulties and barriers to developing these general principles. In reporting on this, experiences and behaviors in recent years are generally brought up: strategies for economic development - recently, the strategic priorities of smart specialization - that governments have taken and generalized with a one-sided model; the organizational process has stabilized the distribution of competences and the complex institutional organization; public administrations are understood as service trainers and have become the main customers of many companies; the responsibilities, functions, and goals of the agents of the innovation system are blurred; the strategies of territorial agents are often dependent on their structure and on the spending of the organization, thus strategies are usually designed based on public subsidies, and many calls are also designed for ad hoc agents; the criteria for measuring project impacts on public programs and announcements have been bureaucratized and are alienated from the logistics of market dynamics; the culture of impact assessment is limited and program results regarding relationships among agents or the efficiency of the economy have fallen into second place. As an example of this, for instance, inputs were measured in technological centers ( $R \& D$, European projects) but outputs and effects (creation of new technology companies, number of jobs, transfer to businesses, market recruitment, personal mobility to private companies) were then not measured. 
These experiences and behaviors, however, have adverse effects: separating agent activity from market dynamics; restricting improvements in corporate organization, familiarity with market customers, the quality of services, and technological innovation; missing the chance to turn new social and economic opportunities into a niche market.

However, declaring the company to be a central agent in competitiveness strategies does not bring about economic self-regulation. Those who use this viewpoint as a main premise carry out a more complex reading. On the one hand, being familiar with the market and differentiating oneself from competitors and being able to provide customer solutions require a variety of measures from companies, some related to financing and the business model (comprehensive service, complete availability, adaptability to customer needs), others associated with company organization and management: reinforcing and maintaining investments in $\mathrm{R} \& \mathrm{D}$, providing resources for professional training and languages, and delving into teamwork resources, opportunities, and incentives. On the other hand, however, in order for companies to create value in the market, public policies also need to expand their competitiveness strategies, for example, by insuring anchor companies, defining the responsibilities of agents in the innovation chain, strengthening capabilities related to solutions in the innovation chain, added value, and engineering, and helping dynamic sectors and new businesses with public funds.

Also, according to this point of view, governments and public policies have a decisive responsibility in areas that channel companies toward competitiveness, such as in promoting knowledge and technology, financing, directing entrepreneurial companies, attracting and retaining talent, governance among agents of the innovation system, attracting investment, and facilitating various resources for expanding new markets (advice, services, international promotion, subsidies, sponsorship in bidding). In this sense, competitiveness and innovation strategies can also be understood and recognized as regulatory and incentive measures to improve companies' capabilities.

In the end, it would be companies that would have to develop strategies to compete in the market, and they would have a special responsibility to clarify agents' roles and align strategies in the territorial knowledge and innovation system. In light of this, anchor companies would be identified so they can drive the value chain and transform the industrial production fabric in its entirety into digital technology. According to this, business and entrepreneurship are essential for the development of the territory, but at the same time, companies and their competitiveness are closely linked to the capabilities of the territory, manual labor, and intelligence. It must be recognized finally that the regulation of the economy is contingent upon the relationship of many factors, and that the unique contexts needed for companies to compete in the market are indispensable.

\subsection{Territorial strategy}

One of the other points of view regarding the territory emphasizes the territorial strategy, and interprets the importance of companies in this light. To some extent, this perspective separates business strategy from territorial strategy. Since the aforementioned view also makes a complex reading, the relative positions of territorial agents are complementary, but there are also differences. Indeed, some emphasize and focus on the following idea: the reorganization and revitalization of the productive structure of the territory is due to a variety of agents, policies, and initiatives.

Thus, in the local economy, the regulatory capacity of many agents is recognized and valued. This explains territorial competences, such as population composition, research, transfer, and innovation, and the technological level and internationalization capacity. In this perspective, of course, the cycle of public policies is also more complex. That is, if business strategies are viable, it is essential to develop territorial strategies, for example, training for young people, training, motivation, and education for employed workers, technological and organizational innovation, democratization of companies, relationships among territorial agents and their intensity, quality and density.

According to this, the territorial agent is active and hierarchies in economic regulation are less noticeable and direction-oriented. Furthermore, each territory has its own path, dynamics, and special and unique interactions, and often "path dependency" is as important as decisions made by agents. To some extent, in the territorial innovation system, functional 
differences between agents can lead to alignment difficulties due to limited information, concurrence of interests, or agents' missions, identity, or unclear responsibilities. Likewise, the nature and purpose of territorial development may also be reflected in the views of the agents. The economic agents of the territory are fundamentally diverse in their abilities, functions, competences, and interests.

In order to understand the economic structure of the territory or agree on specialization options, then, it must be acknowledged that competitive factors are abundant. Agents of the competitiveness and innovation system are important, as are territorial companies: organizations related to knowledge (training and education, research, transfer); public institutions and policy; financial entities; mutual guarantee associations; financial markets; public or private funding; companies that develop, market, and innovate products and services in the area of technology; the social fabric and subjective principles in general, such as the entrepreneurial culture, aspiration and vocation of agents, their mutual trust and cooperation, and social capital.

\section{Updating the governance system}

Economic activities concentrate in specific places, the spaces are embodied with the actions of many agents, and both vertical strategies (for companies, sectors, and agents of innovation systems) and horizontal strategies (research and development, clustering, governance) are entwined.

Along these lines, there is unanimous agreement regarding the need to review the programs, tools, resources, and purposes of the territorial innovation system. Similarly, there is also agreement regarding adjusting strategies in the following order: identify challenges; agree upon how to deal with those challenges, taking into account the strengths and weaknesses of the agents; reach agreement regarding how to deal with these challenges; distinguish the organizational structure in the value chain of specialized economic development, as well as agents and responsibilities; and clarify the distribution of labor. However, on the operative plane there are many and varied difficulties. A review of the innovation system places the identities and interests of agents and entities in the same neighborhood; the decision to debate the way the agents act, their structure and organization, nature, purpose, and by extension their meaning, is a difficult and daring one. Likewise, the agents' ways of acting, organization, and interests are not transformed naturally by themselves and in the absence of clarity, collaboration and cooperation become difficult, weakening and eroding frameworks of trust.

At the same time, agents generally share the same weaknesses that are found in government and public administration: the administration is perceived as an organization for redistributing resources, and preparing and managing services; industrial and competitiveness policies are partial or fragmented plans for a particular area or department and there are difficulties in considering general or complete plans; functional differences between agents and administrative culture often break down issues in sectors and this complicates the flow of knowledge, the coordination of services, and interaction or collaboration between agents; competitiveness strategies and logistics of the productive model of the territory are activated in scale and multilevel organizations; and various fields (international commercial and financial relations, currency policy, public finances, macroeconomics) are establishing themselves in very different areas in local governments. Furthermore, there are other problems: citizens, organizations, and professionals pose cognitive boundaries; the views of the actors involved in the decision-making process are volatile; it is difficult to foresee consequences and results; the decentralization dilemma (different levels of government and geographical areas have been integrated into decision-making, as have public, community, and private actors representing a wide variety of people); there are conflicts between objectives and clashes between methods of achieving those objectives.

The role of public administration and reforming responsibility is difficult. The complexities, differences and autonomy of different spheres of society, and the professionalism of the agents in general eliminates the need to replace an omniscient government with very different forms of governance. There is agreement in several different ideas: understanding the importance of context - the importance of the competitiveness ecosystem --; accept the complex nature of processes and become familiar with the territory as a subject; understand government as one more helix of innovation; but at the same time acknowledge the responsibility and leadership 
needed to facilitate relationships, cooperation and trust among agents.

In addition, the territory of Gipuzkoa has many peculiarities: it has several institutional competences for territorial development; the institutional culture in the territory is polycentric and, in many cases, decentralization can facilitate cooperation, networking, and trust among agents; and territorial regions have specialties and this has stabilized physical, social, and emotional closeness. Since governance is an important factor in competitiveness, reformulating these factors in the light of a new context is also a component of strategy.

In order to respond to new challenges among agents, optimism and self-esteem are strong. The general picture is that there are skills to strengthen networks and connections, in the intensity, quality, and sustainability of relationships. One of the strengths of the territory is recognizing the importance of companies, and it has been stated that there has been an attempt to create a systemic vision. The main premise is to agree on strategies to deliver effective and competitive responses to challenges through cooperation. Along the same lines, there are cases of different kinds in the territory that have to do with the alignment of relationships and goals among agents and entities. As an advanced model, they have learned to agree, looking toward the future, on the systematization of innovation and the complementarity between agents and activities. There are many different kinds of advanced models, including the following: the Mondragon Cooperative Experience, Vocational Training (with the initiative of territorial companies, to respond to the evolution of the productive sector and teach and train people through innovative teaching-learning methodologies); the regional alliance of Goierri, and Gipuzkoa online (a new culture to establish a relationship between local and heterogeneous agents in order to consolidate a regional level). In any case, such cases demonstrate that reaching consensus on strategies is an open, long, and fluid process.

\section{Acknowledgments}

This work presents and develops some of the results of research financed by the Etorkizuna Eraikiz - GipuzkoaLab 2016 program of the Directorate-General of Strategic Management of the Gipuzkoa Provincial Council.

\section{References}

Acemoglu, D. and Restrepo, P. (2018). Artificial Intelligence, Automation and Work. No w24196, National Bureau of Economic Research.

Baldwin, R. (2016). The Great Convergence: Information Technology and the New Globalization. Harvard: Harvard University Press.

Castells, M. (ed.) (2018). Europe's Crisis. Cambridge: Polity Press.

Mazzucato, M. (2016). From market fixing to market-creating: a new framework for innovation policy. Industry \& Innovation, 23(2): 140-156. doi.org/10.1080/13662716.2016.1146124

Mazzucato, M. (2018). The Value of Everything: Making and Taking in the Global Economy. London: Allen Lane Penguin.

Morgan, K. (2016). Collective entrepreneurship: the Basque model of innovation. European Planning Studies, 24(8): 1544-1560. doi.org/10.1080/09654313.2016.1151483

Pérez, C. (2002). Technological Revolutions and Financial Capital: The Dynamics of Bubbles and Golden Ages. Cheltenham: Edward Elgar.

Ridao-Cano, R. and Bodewig, C. (2018). Growing United: Upgrading Europe's Convergence Machine. World Bank Report on the European Union. Washington: International Bank for Reconstrucion and Development / The World Bank.

Rodrik, D. (2011). The Globalization Paradox: Democracy and the Future of the World Economy. New York: W.W. Norton.

Rodrik, D. (2018). Straight Talk on Trade: Ideas for a Sane World Economy. Princeton, NJ: Princeton University Press.

Stiglitz, J.E. and Greenwald, B.C. (2014). Creating a Learning Society: A New Approach to Growth. Columbia: Columbia University Press. 
Uyarra, E., K. Flanagan, E. Magro, J. Wilson and M. Sotorauta (2017): Understanding regional innovation policy dynamics: Actors, agency and learning. Environment and Planning C: Politics and Space, 35(4): 559-568. 